\title{
November 2017 Critical Care Case of the Month
}

\section{Stephanie Fountain, MD}

Pulmonary and Critical Care Medicine

Banner University Medical Center Phoenix

Phoenix, AZ USA

\section{History of Present IIIness}

A 56-year-old man presented with "food stuck in throat" since eating steak 18 hours prior to presentation. He is unable to eat or drink and has a sore throat. He is able to speak but has a "hoarse voice." He denied drooling.

\section{Past Medical History, Family History, and Social History}

- He described himself as "healthy" and had not sought medical care in years.

- Former smoker but quit 2 years ago.

- He uses alcohol daily.

- He denied illicit drug use.

\section{Physical Exam}

- Afebrile, blood pressure 137/74 mm HG, heart rate 74 beats/min, SpO2 98\% on room air.

- Physical exam was normal

Which of the following should be done next?

1. Esophagogastroduodenoscopy (EGD)

2. Papain (Adolph's Meat Tenderizer $\AA$ ) administration

3. Tracheostomy

4. 1 and 3

5. All of the above 


\section{Correct! \\ 1. Esophagogastroduodenoscopy (EGD)}

The best choice is EGD. This would allow identification and removal of the suspected food impaction. Papain has been used with mixed success for meat impactions but is probably not appropriate for initial therapy. He has no dyspnea or stridor and there is no indication for an emergency tracheostomy at this time.

His EGD reveals no food impaction or esophageal stricture. He does have diffuse gastritis without ulcers. However, his upper airway is noted to be narrowed and anesthesia is called for elective intubation. They successfully intubated the patient but their note says, "Difficult airway, even with Glidescope. Protect airway at all costs, unlikely to be able to intubate again."

A neck CT scan is performed (Figure 1).

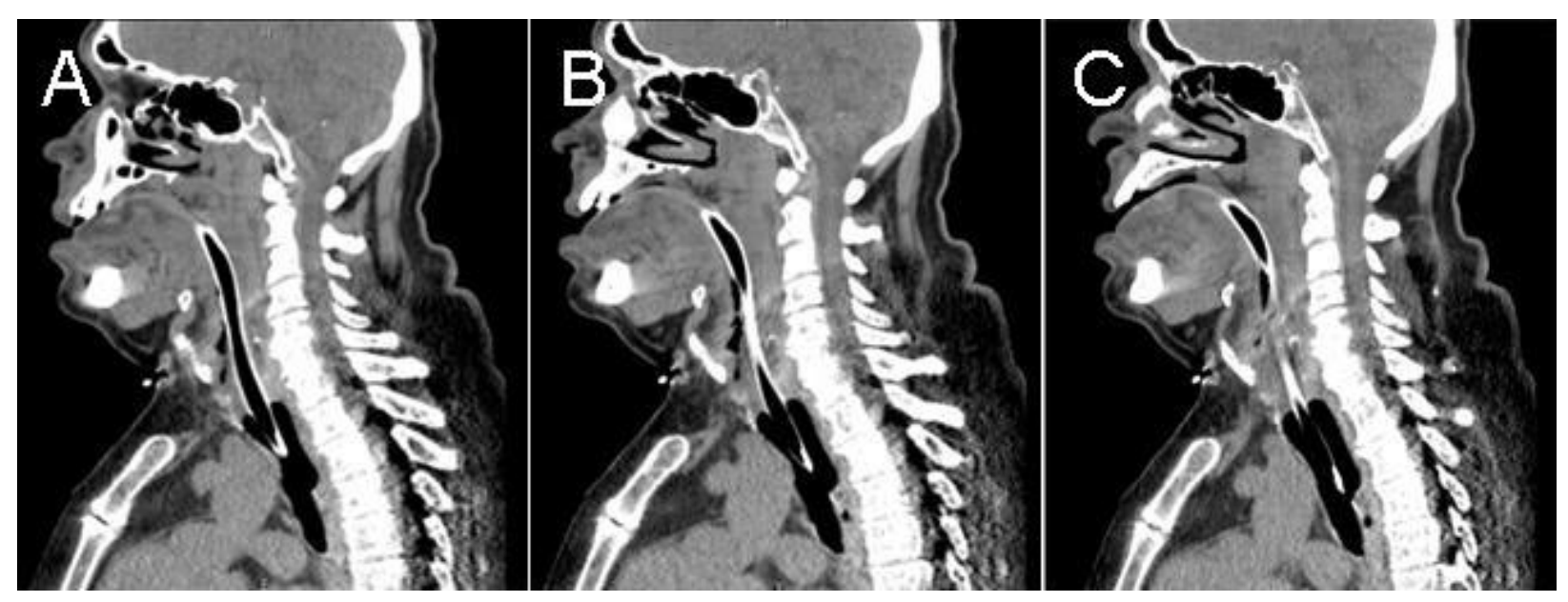

Figure 1. Representative lateral images from the neck CT scan.

What should be done next?

1. Administer antibiotics and corticosteroids

2. Tracheostomy

3. Laryngoscopy

4. 1 and 3

5. All of the above 


\section{Correct!}

\section{1 and 3}

The patient has epiglottitis. Although the position of epiglottis is altered by the endotracheal tube, it is enlarged (Figure 2).

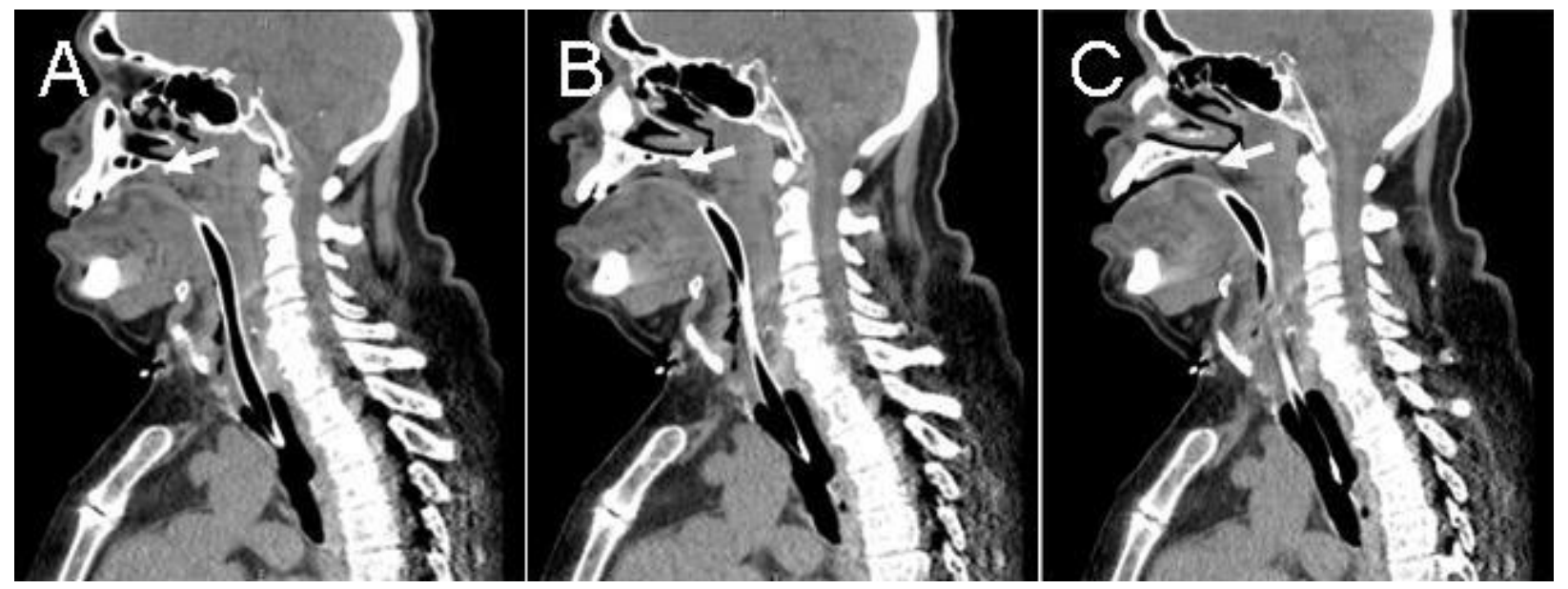

Figure 2. Neck CT scan showing enlarged epiglottis (arrows).

Many would confirm the presence of epiglottitis by direct laryngoscopy (Figure 3).

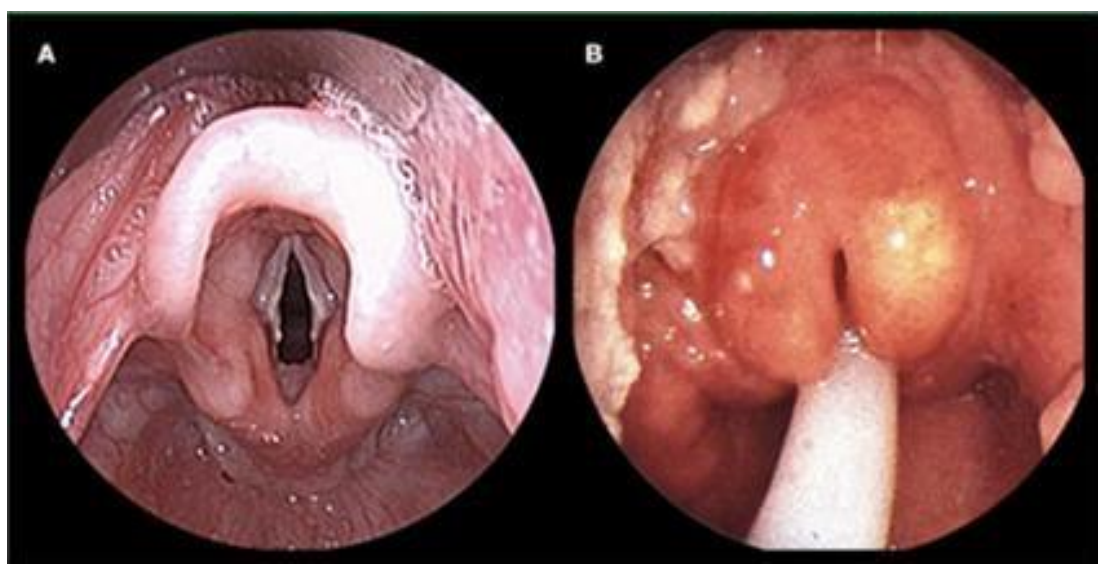

Figure 3. Direct laryngoscopy showing normal epiglottis on the left and an enlarged epiglottis on the right (not this patient) (1).

The epidemiology of epiglottis has changed since the introduction of Hemophilus influenza B vaccine in 1985. The incidence has decreased in children so that now epiglottitis is predominately an adult disease. While the majority of children presented with epiglottitis presented with difficulty breathing and stridor adults present somewhat differently (Table 1). 
Table 1. Common symptoms in adults with epiglottitis.

- Sore throat or odynophagia (90 to 100 percent) out of proportion to exam

- Fever $\geq 37.5^{\circ} \mathrm{C}$ ( 26 to 90 percent)

- Muffled voice (50 to 80 percent)

- Drooling (15 to 65 percent)

- Stridor or respiratory compromise (approximately 33 percent)

- Hoarseness (20 to 40 percent)

The cause of the epiglottitis is infectious in most instances and antibiotics should to cover $\mathrm{H}$. influenza, Streptococcus and Staphylococcus, the three most common bacterial causes. Many still give corticosteroids although trials in children have produced conflicting results (2-4). Many also give epinephrine (4).

Tracheostomy is not necessary in most cases. Most patients can be extubated after 4872 hours if the epiglottic inflammation has been shown to decrease.

Our patient was given corticosteroids and vancomycin, ceftriaxone, and ampicillin/sulbactam. He was breathing comfortably on minimal ventilator settings when his urine output decreased to less than $100 \mathrm{ml} / 8$ hours despite a Foley catheter in place which seemed to be functioning normally. Chest X-ray was unremarkable (Figure 4).

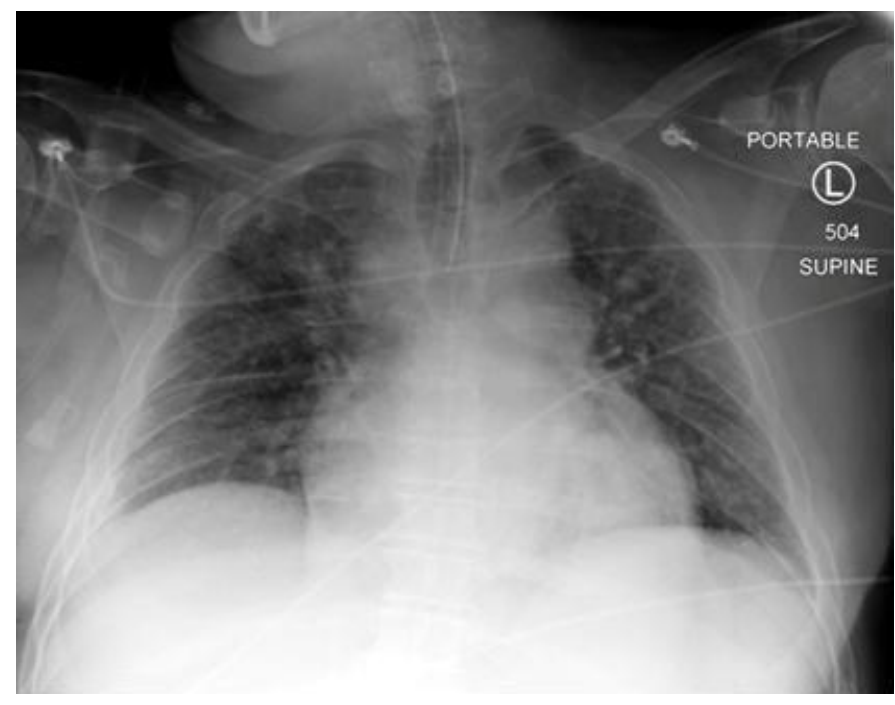

Figure 4. Portable chest radiograph on hospital day 2.

What should be done at this time?

1. Assess fluid status with beside ultrasonography

2. Obtain urinalysis and culture

3. Obtain electrolytes creatinine and BUN

4. 1 and 3

5. All of the above 


\section{Correct! \\ 5. All of the above}

Beside ultrasonography showed the inferior vena cava diameter to be approximately 2.3 $\mathrm{cm}$ (normal $1.5-2.5 \mathrm{~cm}$ in adults). The fractional excretion of sodium (FeNA) was $1.1 \%$, a random urine osmolality was $502 \mathrm{mOsm} / \mathrm{kg}$ of water (normal 300-900) and urine specific gravity was 1.031 (normal 1.000-1.030). Urinalysis is shown in Figure 5.

\begin{tabular}{|c|c|}
\hline \multicolumn{2}{|l|}{ URIINALYSIS } \\
\hline Color, UR & Amber A \\
\hline Appearance, UR & Cloudy A \\
\hline Glucose, UR & Negative \\
\hline $\mathrm{pH}, \mathrm{UR}$ & 5.0 \\
\hline Ketones, UR & Negative \\
\hline Protein, UR & $100 \mathrm{mg} / \mathrm{dL}$ A \\
\hline Bilirubin, UR & Negative * \\
\hline Blood, UR & $1.00($ Large $) \mathrm{mg} / \mathrm{c}$ \\
\hline Urobilinogen, UR & Normal \\
\hline$\square$ Specific Gravity, UR & $1.031 \mathrm{H}$ \\
\hline Nitrite, UR & Negative \\
\hline Leukocyte esterase, UR & Negative \\
\hline WBC, UR & $6-10 /$ HPF A \\
\hline RBC, UR & $>50 / \mathrm{HPF} A$ \\
\hline Squamous Epithelial, UR & $1-5 / \mathrm{HPF}$ \\
\hline \multicolumn{2}{|l|}{ Non-Squamous Epithelial, UR } \\
\hline \multicolumn{2}{|l|}{ Amorphous, UR } \\
\hline Mucus, UR & Present A \\
\hline Bacteria, UR & Many / HPF A \\
\hline Hyaline Cast, UR & \\
\hline
\end{tabular}

Figure 5. Urinalysis obtained on hospital day 2.

A trial of diuretics did not increase urine output. A nephrology consult was obtained and suggested the most likely diagnosis was acute tubular necrosis. The creatinine and blood urea nitrogen were initially normal but continued to rise and hemodialysis was begun. The patient tolerated the hemodialysis well and the urine output was increasing until hospital day 8 . At that time the patient became febrile $39.7^{\circ} \mathrm{C}$, the white blood cell count rose to 13,400 from 2,800 cells per microliter, the heart rate increased to 125 , and the blood pressure decreased to $<90 / 60 \mathrm{~mm} \mathrm{Hg}$. There was also difficulty with the hemodialysis secondary to the filter clotting.

Which of the following are true?

1. A chest $x$-ray should be obtained

2. A CT scan of the abdomen should be performed to look for a source of sepsis

3. Vasopressors should be started

4. 1 and 3

5. All of the above 


\section{Correct! \\ 5. All of the above}

The patient is clinically presenting with septic shock despite broad spectrum antibiotic coverage. Vasopressors were begun and the blood pressure initially increased. A chest $\mathrm{x}$-ray should be obtained because ventilator-associated pneumonia is quite possible given his prolonged intubation (Figure 6).

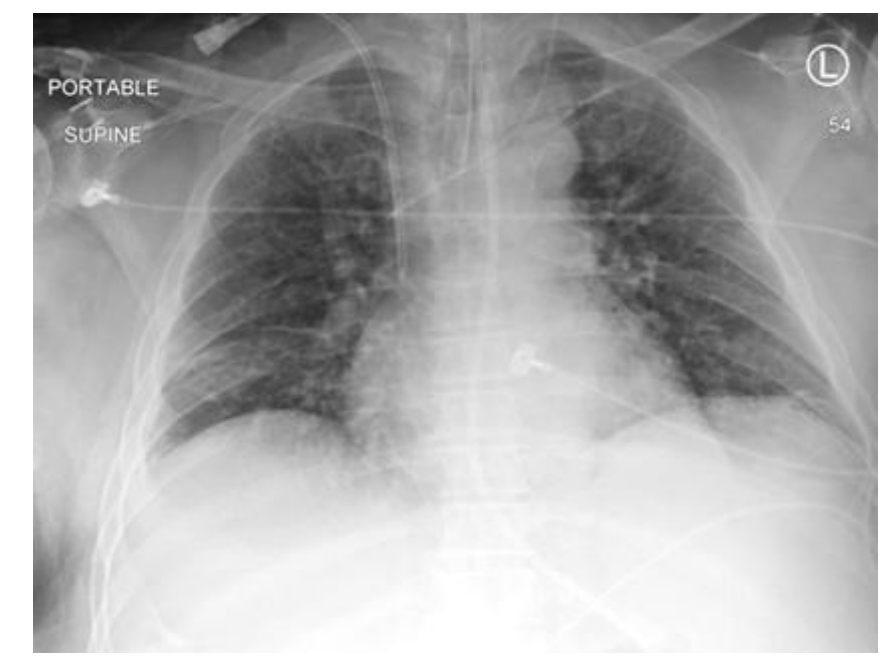

Figure 6. Repeat portable chest radiography on hospital day 8.

To search for a source of sepsis a CT scan was performed (Figure 7).
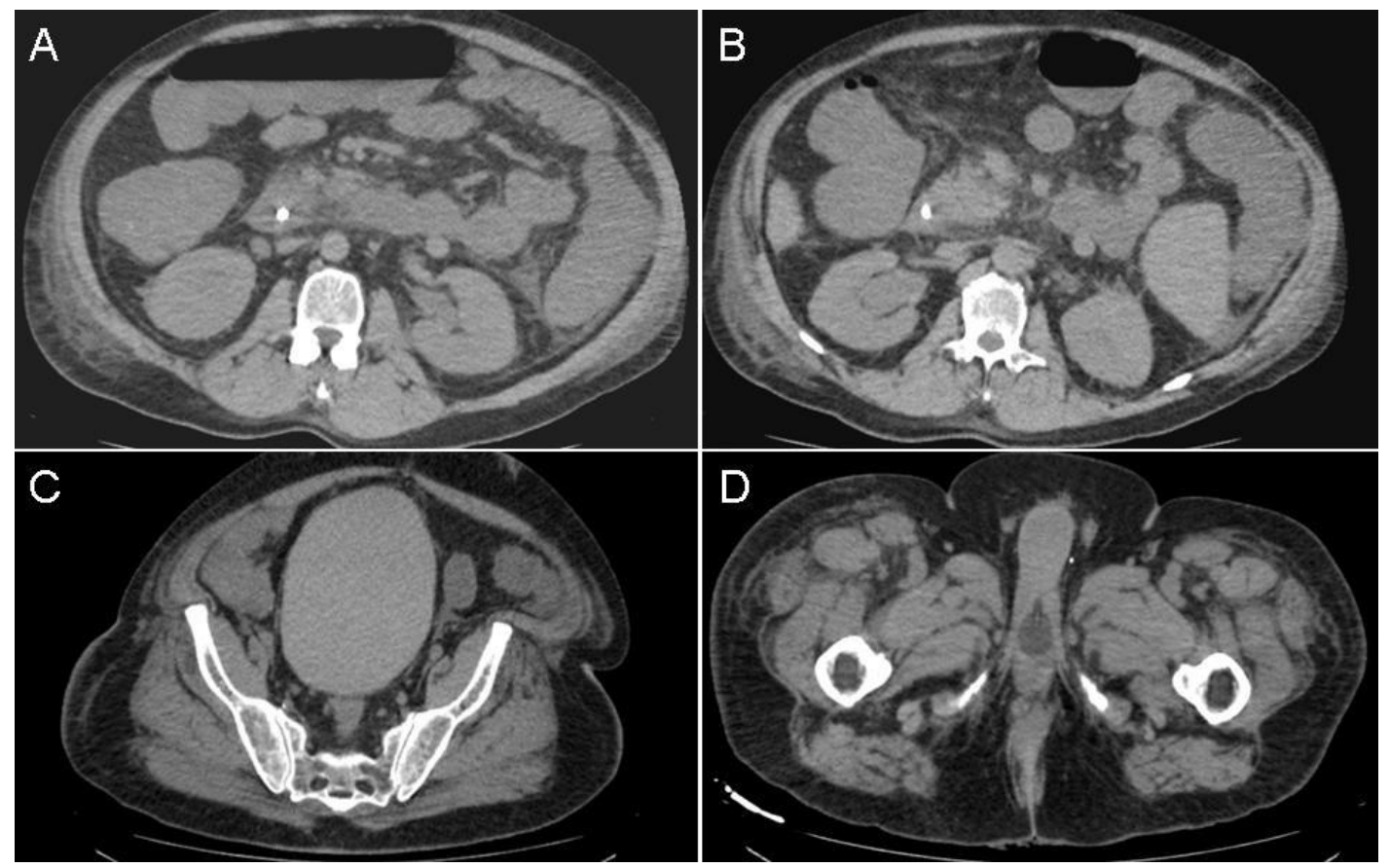

Figure 7. Representative views from the thoracic CT scan without contrast. 
Which of the following are true?

1. The chest $x$-ray shows diffuse consolidation consistent with ventilator-associated pneumonia.

2. The abdominal CT scan shows the balloon of the Foley catheter in the penis with a distended bladder.

3. The patient should be given repeated fluid challenges for his septic shock.

4. 1 and 3

5. All of the above 


\section{Correct! \\ 2. The abdominal CT scan shows the balloon of the Foley catheter in the penis with a distended bladder.}

The chest $x$-ray does not show any definite areas of consolidation. Although repeated fluid boluses were at one time the gold standard for sepsis care, more recent evidence suggests that this might be harmful (5-8). The abdominal CT scan shows the Foley balloon in the penis and the bladder grossly distended. Replacement of the Foley yielded 2 liters of urine. Despite the intervention the patient did poorly and eventually his family wished to withdraw care. A take home point is that in acute renal failure, some imaging technique (ultrasound is often the easiest) should be done to assess for obstruction (9).

\section{References}

1. Woods CR. Epiglottitis (supraglottitis): Clinical features and diagnosis. UpToDate. May 3, 2017. Available at: https://www.uptodate.com/contents/epiglottitissupraglottitis-clinical-features-and-diagnosis (requires subscription, accessed 10/23/17).

2. Geelhoed GC, Macdonald WB. Oral and inhaled steroids in croup: a randomized, placebo-controlled trial. Pediatr Pulmonol. 1995 Dec;20(6):355-61. [CrossRef] [PubMed]

3. Bjornson CL, Klassen TP, Williamson J, et al. A randomized trial of a single dose of oral dexamethasone for mild croup. N Engl J Med. 2004 Sep 23;351(13):1306-13. [CrossRef] [PubMed]

4. Bjornson CL, Johnson DW. Croup in children CMAJ. 2013 Oct 15; 185(15):1317-23. [CrossRef] [PubMed]

5. Durairaj L, Schmidt GA. Fluid therapy in resuscitated sepsis: less is more. Chest. 2008 Jan;133(1):252-63. [CrossRef] [PubMed]

6. Maitland K, Kiguli S, Opoka RO, et al. Mortality after fluid bolus in African children with severe infection. N Engl J Med. 2011 Jun 30;364(26):2483-95. [CrossRef] [PubMed]

7. Andrews B, Semler MW, Muchemwa L, et al. Effect of an early resuscitation protocol on in-hospital mortality among adults with sepsis and hypotension: a randomized clinical trial. JAMA. 2017 Oct 3;318(13):1233-40. [CrossRef] [PubMed]

8. Raschke RA, Kayani A, Sultan S, Fountain S, Abidali M, Henry K. Fluid resuscitation for septic shock - a 50-year perspective: from dogma to skepticism. Southwest J Pulm Crit Care. 2016;13(2):65-70. [CrossRef]

9. Biruh T Workeneh BT. Acute kidney injury workup. Medscape. January 13, 2017. Available at: https://emedicine.medscape.com/article/243492-workup (accessed 10/23/17). 